\title{
Progress in Turkish International Relations
}

\author{
İlter Turan \\ Bilgi University
}

\begin{abstract}
There are certainly grounds for optimism when it comes to progress in Turkish international relations (IR). Turkish academia has come a long way since the 1960s. The rapid expansion of IR study in Turkish academia can be attributed to the expansion in the Turkish educational system, especially after 1980, and the rising importance of international relations through globalization. Turkish society has very large potential for future work in $I R$, with many highly qualified scholars. Compared to a few decades ago, more IR articles are being authored by Turkish scholars, both abroad and in Turkey. The question now is how Turkish scholars can become an even stronger voice in the international academic community. In this paper, I suggest better collaboration with government and universities to develop better PhD programs, participate in PhD consortiums and establish stronger links with the international community.
\end{abstract}

Keywords: Scientific progress, Turkey, international relations, professional organization, academic community, science policy

\section{Progress and Policy Relevance}

Owing to the necessity of preventing another world war, the global IR discipline has recently come into its own, striving to produce relevant and actionable knowledge about the world's most urgent problems. The extent of progress in achieving this aim depends very much on the interaction between scholars and policymakers. Political science scholars who study IR interact with policymakers in many ways. In some instances, it is a symbiotic relationship because IR scholars depend on input from policymakers to do their job. And reciprocally, policymakers often need the contributions of scholars to carry out their own work. Policymakers benefit from following the scholarly developments in their field, but often they do not have the time to do so. An increased level of interaction, however, would depend on the nature and type of IR studies and the directions in which they are progressing.

Some studies focus on developing theories, the direct relevance of which may not be apparent to policymakers at first glance. Other scholars specialize in policy-making questions and are expert in policy areas, giving them an advantage over government policymakers because they have more time to collect information from a wide variety of sources. These scholars may contribute substantially to policymaking and implementation. Other foci of IR include the art of negotiation, which concentrates on negotiation techniques and peaceful 
conflict resolution. Such studies are extremely useful and beneficial for policymakers. An intriguing and critical question, of course, is whether policymakers have enough time to read these scholarly works and, given how IR has developed over time, whether they are equipped to understand what they read. For example, a scholarly work that employs complicated mathematical techniques requires specialized knowledge to follow its arguments and analyses, which a non-academic policymaker may lack. If presented in ways the policymaker would comprehend, then he or she would be able link the implications of the quantitative research or formal models to his or her needs. We need to make more efforts in this direction.

The progress of the study of IR in Turkey can be evaluated by looking at the history of its development with regard to training, research and employment opportunities. In this commentary, I shall also offer some ideas to improve the shortcomings related to the discipline in Turkey.

\section{The Expansion of the Study of International Relations in Turkey}

Analyzing the history of IR in Turkey, it is evident that teaching programs were originally developed to train qualified diplomats. For this reason, the initial curricula were mainly designed to cover topics of import to diplomatic personnel. The training function was almost exclusively discharged by the Faculty of Political Science at Ankara University, and the curriculum was a combination of Diplomatic History, International Law and International Politics, with the last course added as the discipline began to develop rapidly after World War II. Today, another increased expansion in Turkish IR may be observed in academia, which is a result of two major developments. The first is the expansion of the Turkish university system, especially after 1980 . Currently, the number of universities approach 200 . The second comprises a number of developments: the rising importance of IR through globalization, Turkey's integration into the global economic system, its rapid economic development and its growing role in regional integration projects. The increase in the development of new academic programs in a number of universities, such as European Union Studies, is an example of this expansion.

Employment opportunities for graduates of IR departments have also increased over time, something of great importance to students. Of course, there is not always a one-to-one correspondence between what one studies in college and what kind of a job one gets, but an IR degree is deemed appropriate training for a considerable array of jobs.

I should note that there is a fancy quality to the term International Relations. For example, many institutions have separate departments for Political Science and International Relations, but when the two curricula are compared, there are few differences. In fact, if a student takes a few additional courses from the sister department, he or she will have the training for everything required for either a Political Science or an International Relations degree. However, the minimum admission score required for getting into an IR program is generally higher than that for Political Science. This difference could be attributed to the aforementioned 'fancy name effect' or perhaps simply to the effect of globalization on what to study. The number of IR departments in Turkey is far fewer than the number of Public Administration or Political Science departments. This may mean that fewer graduates of IR are needed, or it may well mean that it is more difficult to build an IR department. The difference in numbers may reflect different levels of need, but it may also reflect the greater difficulty in finding schools in which to pursue IR undergraduate and graduate studies in Turkey. 
The developments referred to above already indicate that the discipline has expanded in terms of the number of schools, subjects and staff in recent years. Such quantitative expansion does not automatically translate into scholarly progress, however. If we take the number of international publications as an important indicator of scholarly achievement, we see that nowadays compared to earlier times, one is more likely to come across IR articles by scholars of Turkish origin working abroad or Turkish scholars living in Turkey. The small number of foreign scholars working in various Turkish institutions can be added to this figure. Still, I am not aware of a major contribution by Turkish scholars to what we call the grand theories of IR. This fact might be related to the limited availability (until recently) of data on the periphery of global scholarly communication networks. Although more data is available today than in the past, opportunities such as frequent contact with international organizations, influential NGOs and corporations are fewer in Turkey than in major world centers such as London, Paris, Washington, D.C. and possibly Moscow. Support for research is also lacking, unlike, for example, in the US, where scholars have the funds to produce research with a broader scope. Despite these challenges, however, the direction of development in Turkey seems satisfactory in that Turkish scholars now are very much a part of an international community that studies IR.

\section{Barriers to Progress}

In earlier times, scholars from different parts of the world felt it difficult to break into the major scholarly communities in many academic disciplines because these groups were at the same time national communities that were not interested in including others in their ranks. With a closer look, however, this situation may have been more due to poorer communications rather than a conscious effort to keep foreign scholars out. In my experience, the scholarly community seems to encourage intermingling, finding it enriching and a source of pride. The numbers of scholars in any country also play a part; for example, as the US has the most IR scholars of any country, American scholars will be publishing more works than scholars from other countries. Further, American, British and French scholars are professionally much better organized than those in other countries; Turks seem particularly bad at running professional organizations. Common issues are the lack of willingness to pay dues and to produce highquality papers for nationally organized conferences. As most scholars (especially in IR) want to reach a world bigger than Turkey, such issues result in a negligence that reflects on the quality of works in Turkish. A large community with effective internal communications creates research communities or sub-communities that tend to act together and to move ahead; and this is something we need to work on in Turkey.

Another way to encourage collaboration and scientific progress is to allocate research grants to promote the study of specific topics. Many agencies in the US and in the EU offer grants to help researchers with their work. Unfortunately, we do not have the same tradition in Turkey. Turkish scholars usually invest a lot more effort doing research and possibly get less done than an American- or a EU-based scholar because the grants made available to the latter enable them to hire research assistants, conduct surveys, and perform other work that facilitates and expedites data collection, management and analysis.

Moreover, data is also easier to secure in the US and the EU compared to Turkey. A researcher in these countries interested in a specific topic can establish friendly linkages with an organization that focus on that topic and gain direct access to a large amount of data. 
For example, since the World Bank is in Washington, it is arguably easier for an American researcher to access their unpublished data. In general, researchers in major world centers have more contact with researchers and other staff working for these organizations. Their common interests can result in increased interaction and sometimes joint research and publications. There is also a lot of mobility between government, private research agencies and academia in these countries, an option generally less available to Turkish researchers.

Another barrier is language. For example, English journals and reviewers (which comprise the majority of professional journals) are not likely to publish papers written by non-native English speakers that contain grammar errors and poor forms of expression. Further, although there is a process of anonymous review, it is often possible to guess where the author originates based on his or her language, and it is commonly observed that people (i.e. editors) are generally favorably disposed toward the familiar (i.e. English). To combat this issue, Turkish institutions could extend editing support for scholars wishing to publish in international journals. Material limitations may also act as a barrier. For example, attending international symposia and conferences is more difficult for many Turkish than American or EU scholars because funds for such activities are more readily available there than in Turkey. I am happy to note that there are more funds available for taking part in international meetings now than in the past. Finally, the community of IR scholars in Turkey continues to be small. In addition, many scholars are overburdened with teaching. Under the circumstances, their output of research and writing tends to be just enough to get their next promotion rather than a sustained and patterned activity.

In conclusion, rather than a systematically established system of barriers that may stand in the way of scholars from Turkey or another country in producing globally acclaimed works, there are a number of empirical factors that have proven dysfunctional for productivity and high quality in Turkey, and may apply to other countries as well.

\section{Towards a More Integrated Community}

I would like to offer some suggestions for solving the above-mentioned problems so as to create opportunities for Turkish IR scholars to become more integrated with the global IR community. An important one is active membership in and consistent attendance at professional meetings in order to become and remain within the IR communication network. Membership to most institutions costs over $\$ 100$ annually, and these rates increase with subscriptions to scientific journals. This amount might not seem very high, but it is a significant amount for a young Turkish scholar, especially if he or she wishes to belong to more than one organization. There is currently no support in Turkey to link scholars to the network of international organizations. The universities can provide the financial support needed a step that would greatly further Turkish contributions to IR.

Second, to help Turkish scholars organize domestically, the story of the International Political Science Association (IPSA) may be instructive. The association was established by the United Nations Educational, Scientific and Cultural Organization (UNESCO) after World War II to promote the development of an international community of scholars. The initiative was not limited to scholars of political science, but also included the development of professional associations in sociology, economics and disciplines in the positive sciences and engineering. UNESCO provided the seed money for scholars to meet, but over the years 
IPSA has become independent of UNESCO, which today does not even have the means to extend support to IPSA and others even if it wished to.

To support a domestic organization of scholars, the Turkish government could offer help in organizing national scientific communities. One of the major problems in organizing such associations in Turkey is that political divisions outside a community tend to be replicated inside a community. Although professional disciplines are not arenas in which to debate national politics, many academics do not accept this. To encourage neutral associational development, the government could implement changes in the law of associations to promote the expansion of professional organizations. For example, the government could also encourage universities to provide space or secretarial help for these organizations. As an external example, the headquarters of IPSA are at Concordia University in Montreal, Quebec, thanks to the support of the university and the municipal and provincial governments; IPSA receives free rent and other necessary facilities from Concordia University, along with a faculty member who works half time at Concordia and the other half as IPSA's secretary general. A rare example of such cooperation in Turkey is the International Relations Council Association (Uluslararası Ilisskiler Konseyi Derneği), which exists thanks to the efforts of Mustafa Aydin, rector of Kadir Has University, who donates some labor and, I believe, some space at the university. Such support from external sources clearly contributes to the faster evolution of a scholarly community in a particular field, and in turn, the quicker advancement of research and development of that field through the commitment of the scholars themselves. In contrast, the Turkish Political Science Association (Türk Siyasi Ilimler Derneği), for example, does not have a secretariat, therefore is not effective in collecting membership dues and its activities remain limited.

Last, the quality of education is an issue that directly affects the development of any field. The sufficiency of Turkish investment in the quality of future IR scholars is an important question. Unfortunately, the simple answer is that the investment is not sufficient. The monitoring of quality is also neglected. It seems that having $\mathrm{PhD}$ programs is a matter of prestige for universities independent of whether they can actually undertake them. This is no less true in the field of IR. One of the main insufficiencies in Turkey is the small number of academic staff. The numbers are simply few to meet the needs of operating a satisfactory program. A related obstacle is the lack of instructors with notable achievements. One way of enhancing quality is to have inter-university consortia for $\mathrm{PhD}$ programs in specific urban centers, rather than each university trying to develop its own $\mathrm{PhD}$ program with insufficient resources. A set of standard requirements can be established for choosing instructors to teach in the $\mathrm{PhD}$ programs, such as a track record of successful research and publications. There are many PhD's from prestigious foreign institutions. If implemented, such consortia can have several positive impacts on the future progress of the IR field in Turkey. First, a consortium would expand the resources available to all participating institutions for a $\mathrm{PhD}$ program. Second, the consortium could be granted funding to send graduate students to international conferences to attend panels, present papers etc. Third, the consortium could allow students several months for training and/or research in other countries. These opportunities would provide the new generation with broader and more diverse knowledge in IR, allow them to create a community network at the start of their careers and fill gaps in Turkish academia. $\mathrm{PhD}$ programs should be considered a worthy challenge rather than an opportunity to gain prestige. If an institution has limited resources, and does not take its $\mathrm{PhD}$ program seriously, 
the graduates will be of low quality and the students they teach will be of even worse quality, which will lead to a vicious cycle of underdevelopment.

Despite the above challenges, there are certainly grounds for optimism about the study of international relations in Turkey. When I started in 1964 as a graduate assistant in the Faculty of Economics at İstanbul University, few people worked in the field, there were few Turkish books on the subject, and little research was being done. Since then, Turkish academia has far surpassed that state in terms of both quality and quantity. Change is in a positive direction, and now we need to make things better. With many highly qualified scholars, Turkish academia has great potential and we must become an even stronger voice in the international academic community through organizing more effectively, mobilizing institutional, governmental and private support, creating better $\mathrm{PhD}$ programs and intensifying multiple links with the international community. 